\title{
Fixed Point Theorem in Partial Metric Spaces
}

\author{
R. Krishnakumar ${ }^{1}$, R. Livingston ${ }^{2 *}$ \\ ${ }^{1}$ PG \& Research Department of Mathematics, Urumu Dhanalakshmi College, Tiruchirappalli, India \\ $2^{*}$ Department of Mathematics, Urumu Dhanalakshmi College, Tiruchirappalli, India \\ *Corresponding Author: livi.vedham@gmaill.com, Tel.: 9994970683 \\ Available online at: www.isroset.org
}

Accepted 07/Aug/2018, Online 30/Aug/2018

Abstract - In this paper, we proved the common fixed point theorems for sequence of mappings in Partial Metric Spaces.

Keywords_Partial Metric Space, Complete Patial Metric Space, Coincidence Point, Weakly Compatible, Fixed Point.

\section{INTRODUCTION}

The study of fixed point theorems of maps satisfying contractive type conditions in partial metric spaces has been a very active field of research activity recently. Partial metric spaces were introduced by Mathews[15] in 1992, and proved common fixed point theorems for compatible maps in partial metric spaces. In fact, it is widely recognized that partial metric spaces play an important role in constructing models in the theory of computation.

Definition 1.1: A partial metric on a nonempty set $X$ is a function $p: X \times X \rightarrow R_{+}$such that for all $x, y, z \in X$ :

(p1) $x=y \Leftrightarrow p(x, x)=p(x, y)=p(y, y)$,

(p2) $p(x, x) \leq p(x, y)$,

(p3) $p(x, y)=p(y, x)$,

(p4) $p(x, y) \leq p(x, z)+p(z, y)-p(z, z)$

A partial metric space is a pair $(X, p)$ such that $X$ is a nonempty set and $p$ is a partial metric on $X$.

Remark 1.2: It is clear that, if $p(x, y)=0$, then from (p1) and (p2), $x=y$. But if $x=y, p(x, y)$ may not be 0 . A basic example of a partial metric space is the pair $\left(R_{+}, p\right)$, where $p(x, y)=\max \{x, y\}$ for all $x, y \in R^{+}$. Each partial metric $p$ on $X$ generates a $T_{0}$ topology $\tau_{p}$ on $X$ which has a base the family of open $p$ - balls $\left\{B^{p}(x, \varepsilon), x \in X, \varepsilon>0\right\}$ where $B^{p}(x, \varepsilon)=$ $\{y \in X: p(x, y)<p(x, x)+\varepsilon\}$ for all $x \in X$ and $\varepsilon>0$.

If $p$ is a partial metric on $X$, then the function $p^{s}: X \times X \rightarrow R^{+}$given by $p^{s}(x, y)=2 p(x, y)-p(x, x)-p(y, y)$ is a metric on $X$.

Definition1.3: let $(X, p)$ be a partial metric space and $\left\{x_{n}\right\}$ be a sequence in $X$. Then

(1) $\left\{x_{n}\right\}$ converges to a point $x \in X$ if and only if $p(x, x)=\lim _{n \rightarrow+\infty} p\left(x, x_{n}\right)$

(2) $\left\{x_{n}\right\}$ is called a Cauchy sequence if there exists (and is finite) $\lim _{n, m \rightarrow+\infty} p\left(x_{n}, x_{m}\right)$.

Definition1.4: A partial metric space $(X, p)$ is said to be complete if every Cauchy sequence $\left\{x_{n}\right\}$ in $X$ converges, with respect to $\tau_{p} \quad, \quad$ to $\quad$ a $\quad$ point $\quad x \in X \quad$ such that

$$
p(x, x)=\lim _{n, m \rightarrow+\infty} p\left(x_{n}, x_{m}\right)
$$

Remark1.5: It is easy to see that every closed subset of a complete partial metric space is complete.

Lemma 1.6: Let $(X, p)$ be a partial metric space. Then

(1) $\left\{x_{n}\right\}$ is a Cauchy sequence in $(X, p)$ if and only if it is a Cauchy sequence in the metric space $\left(X, p^{s}\right)$,

(2) $(X, p)$ is complete if and only if the metric space $\left(X, p^{s}\right)$ is complete. Further more $\lim _{n \rightarrow+\infty} p^{s}\left(x_{n}, x\right)=0$ if and only if $p(x, x)=\lim _{n \rightarrow+\infty} p\left(x_{n}, x\right)=\lim _{n, m \rightarrow+\infty} p\left(x_{n}, x_{m}\right)$.

Mathews[15] obtained the following Banach fixed point theorem on complete partial metric spaces.

Theorem 1.7: Let $f$ be a mapping of a complete partial metric space $(X, p)$ into itself such that there is a real number $c$ with $0 \leq c<1$, satisfying for all $x, y \in X, p(f x, f y) \leq c p(x, y)$. Then $f$ has a unique fixed point. 


\section{MAIN RESULT}

Definition 2.1: Let $X$ be a non-empty set and $T_{1}, T_{2}: X \rightarrow X$ are given self maps on $X$. If $w=T_{1} x=T_{2} x$ for some $x \in X$, then $x$ is called a coincidence point of $T_{1}$ and $T_{2}$ and $w$ is called a point of coincidence of $T_{1}$ and $T_{2}$.

Definition 2.2: Let $X$ be a non-empty set and $T_{1}, T_{2}: X \rightarrow X$ are given self maps on $X$. The pair $\left\{T_{1}, T_{2}\right\}$ is said to be weakly compatible if $T_{1} T_{2} t=T_{2} T_{1} t$, whenever $T_{1} t=T_{2} t$ for some $t$ in $X$.

Our main result is the following:

Theorem 2.3: Suppose that $\left\{A_{i}\right\},\left\{A_{j}\right\}(i \neq j) . S, T$ are self maps of a complete partial metric space $(X, p)$ such that $A_{i} X \subseteq T X, A_{j} X \subseteq S X \quad(i \neq j)$ and for all $x, y \in X$, where $\phi \in \phi$

$p\left(A_{i} x, A_{j} y\right) \leq \phi\left(\max \left\{p(S x, T y), p\left(A_{i} x, S x\right), p\left(A_{j} y, T y\right)\right\}\right)$

If one the ranges $A_{i} X, A_{j} X, T X$ and $S X$ is a closed subset of $(X, p)$, then

(1) $A_{i}$ and $S$ have a coincidence point, $(i \neq j)$

(2) $A_{j}$ and $T$ have a coincidence point. Moreover, if the pairs $\left\{A_{i}, S\right\}$ and $\left\{A_{j}, T\right\}(i \neq j)$ are weakly compatible, then $A_{i}, A_{j}(i \neq j), T$ and $S$ have a unique common fixed point.

Proof: let $x_{0}$ be an arbitrary point in $X$. Since $A_{i} X \subseteq T X$, there exists $x_{1} \in X$ such that $T x_{1}=A_{i} x_{0}$. Since $A_{j} X \subseteq S X$, there exists $x_{2} \in X$ such that $S x_{2}=A_{j} x_{1}(i \neq j)$. Continuing this process, we can construct sequences $\left\{x_{n}\right\}$ and $\left\{y_{n}\right\}$ in $X$ defined by $y_{2 n}=T x_{2 n+1}=A_{i} x_{2 n}, y_{2 n+1}=S x_{2 n+2}=A_{j} x_{2 n+1}$

For every $n \in N(i \neq j)$.

We claim that $\left\{y_{n}\right\}$ is a Cauchy sequence in the partial metric space $(X, p)$.

We have : for $(i \neq j)$,

$$
\begin{aligned}
p\left(y_{2 p}, y_{2 p+1}\right) & =p\left(A_{i} x_{2 p}, A_{j} x_{2 p+1}\right) \\
& \leq \phi\left(\max \left\{p\left(S x_{2 p}, T x_{2 p+1}\right), p\left(A_{i} x_{2 p}, S x_{2 p}\right), p\left(A_{j} x_{2 p+1}, T x_{2 p+1}\right)\right\}\right) \\
& \leq \phi\left(\max \left\{p\left(y_{2 p-1}, y_{2 p}\right), p\left(y_{2 p}, y_{2 p-1}\right), p\left(y_{2 p+1}, y_{2 p}\right)\right\}\right) \\
& \leq \phi\left(\max \left\{p\left(y_{2 p-1}, y_{2 p}\right), p\left(y_{2 p+1}, y_{2 p}\right)\right\}\right)
\end{aligned}
$$

Now, we get

$p\left(y_{2 p}, y_{2 p+1}\right) \leq \phi\left(\max \left\{p\left(y_{2 p-1}, y_{2 p}\right), p\left(y_{2 p+1}, y_{2 p}\right)\right\}\right)$

Similarly, we obtain

$p\left(y_{2 p+1}, y_{2 p+2}\right) \leq \phi\left(\max \left\{p\left(y_{2 p}, y_{2 p+1}\right), p\left(y_{2 p+1}, y_{2 p+2}\right)\right\}\right)$

Therefore, from (2.3) and (2.4),

$p\left(y_{n}, y_{n+1}\right) \leq \phi\left(\max \left\{p\left(y_{n-1}, y_{n}\right), p\left(y_{n}, y_{n+1}\right)\right\}\right)$ for sufficiently large $n$.

Suppose that there exists $p \in N$ such that $p\left(y_{2 p-1}, y_{2 p}\right)=0$. Then we have $y_{2 p-1}=y_{2 p}$ and from (2.3), we obtain $p\left(y_{2 p}, y_{2 p+1}\right) \leq \phi\left(p\left(y_{2 p}, y_{2 p+1}\right)\right)$.

Since $\phi(t)<t$ for each $t>0$, the above inequality implies that $p\left(y_{2 p}, y_{2 p+1}\right)=0$ and then $y_{2 p}=y_{2 p+1}$. From (2.4), we get $p\left(y_{2 p+1}, y_{2 p+2}\right) \leq \phi\left(p\left(y_{2 p+1}, y_{2 p+2}\right)\right)$, which implies that $y_{2 p+1}=y_{2 p+2}$.

Hence, we have $y_{2 p-1}=y_{2 p}=y_{2 p+1}=y_{2 p+2}=\cdots$.

Then $\left\{y_{n}\right\}$ is a Cauchy sequence in $(X, p)$. The same conclusion holds if we suppose that there exists $p \in N$ such that $p\left(y_{2 p}, y_{2 p+1}\right)=0$.

Now, we assume that

$p\left(y_{n}, y_{n+1}\right)>0$, for sufficiently large $n$.

Then from (2.5), as $\phi(t)<t$ for each $t>0$, we have

$p\left(y_{n}, y_{n+1}\right) \leq \max \left\{p\left(y_{n-1}, y_{n}\right), p\left(y_{n}, y_{n+1}\right)\right\}$

Hence we get $p\left(y_{n}, y_{n+1}\right)<p\left(y_{n-1}, y_{n}\right)$.

Therefore, $\max \left\{p\left(y_{n-1}, y_{n}\right), p\left(y_{n}, y_{n+1}\right)\right\}=p\left(y_{n-1}, y_{n}\right)$ for sufficiently large $n$.

Thus from (2.5),

$p\left(y_{n}, y_{n+1}\right) \leq \phi\left(p\left(y_{n-1}, y_{n}\right)\right)$ for sufficiently large $n$.

Repeating this inequality $n$ time we obtain

$p\left(y_{n}, y_{n+1}\right) \leq \phi^{n}\left(p\left(y_{0}, y_{1}\right)\right)$.

By the properties (p2) and (p3) we have

$\max \left\{p\left(y_{n}, y_{n}\right), p\left(y_{n+1}, y_{n+1}\right)\right\} \leq p\left(y_{n}, y_{n+1}\right)$. 
Thus from (2.8),

$\max \left\{p\left(y_{n}, y_{n}\right), p\left(y_{n+1}, y_{n+1}\right)\right\} \leq \phi^{n}\left(p\left(y_{0}, y_{1}\right)\right)$.

Therefore,

$p^{s}\left(y_{n}, y_{n+1}\right)=2 p\left(y_{n}, y_{n+1}\right)-p\left(y_{n}, y_{n}\right)-p\left(y_{n+1}, y_{n+1}\right) \leq 2 p\left(y_{n}, y_{n+1}\right)+p\left(y_{n}, y_{n}\right)+p\left(y_{n+1}, y_{n+1}\right) \leq 4 \phi^{n}\left(p\left(y_{0}, y_{1}\right)\right)$

Now by triangle inequality for the metric $p^{s}$ and (2.9) for any $k, n \in N^{*}$ we have

$p^{s}\left(y_{n}, y_{n+k}\right) \leq p^{s}\left(y_{n}, y_{n+1}\right)+p^{s}\left(y_{n+1}, y_{n+2}\right)+\cdots+p^{s}\left(y_{n+k-1}, y_{n+k}\right)$

$\leq 4 \phi^{n}\left(p\left(y_{0}, y_{1}\right)\right)+4 \phi^{n+1}\left(p\left(y_{0}, y_{1}\right)\right)+\cdots+4 \phi^{n+k-1}\left(p\left(y_{0}, y_{1}\right)\right)$

$$
\begin{aligned}
& \leq 4\left(\sum_{i=n}^{n+k-1} \phi^{i}\left(p\left(y_{0}, y_{1}\right)\right)\right) \\
& \leq 4\left(\sum_{i=n}^{\infty} \phi^{i}\left(p\left(y_{0}, y_{1}\right)\right)\right)
\end{aligned}
$$

Hence and from the property (b) of $\phi$ we conclude that for an arbitrary $\varepsilon>0$ there is a positive integer $n_{0}$ such that $p^{s}\left(y_{n}, y_{n+k}\right)<\varepsilon$ for every $n \geq n_{0}$ and all $k \in N$.

Thus we proved that $\left\{y_{n}\right\}$ is a Cauchy sequence in the metric space $\left(X, p^{s}\right)$. Since $(X, p)$ is complete, then from lemma (1.6) $\left(X, p^{s}\right)$ is a complete metric space. Therefore, the sequence $\left\{y_{n}\right\}$ converges to some $y \in X$, that is, $\lim _{n \rightarrow+\infty} p^{s}\left(y_{n}, y\right)=0$.

From the properties (b) in above lemma, we have

$p(y, y)=\lim _{n \rightarrow+\infty} p\left(y_{n}, y\right)=\lim _{m \geq n \rightarrow+\infty} p\left(y_{n}, y_{m}\right)$

Moreover, since $\left\{y_{n}\right\}$ is a Cauchy sequence in the metric space $\left(X, p^{s}\right)$, then $\lim _{n, m \rightarrow+\infty} p^{s}\left(y_{n}, y_{m}\right)=0$ and so from $(2.9)$ and the property (b) of lemma (1.6) we have

$\lim _{n \rightarrow+\infty} p\left(y_{n}, y_{n}\right)=0$.

Thus from the definition of $p^{s}$ and (2.11), we have

$\lim _{m \geq n \rightarrow+\infty} p\left(y_{n}, y_{m}\right)=0$.

Therefore, from (2.10), we have

$p(y, y)=\lim _{n \rightarrow+\infty} p\left(y_{n}, y\right)=\lim _{m \geq n} p\left(y_{n}, y_{m}\right)=0$.

This implies that

$\lim _{n \rightarrow+\infty} p\left(y_{2 n}, y\right)=\lim _{n \rightarrow+\infty} p\left(y_{2 n-1}, y\right)=0$

Thus from (2.13) we have

$\lim _{n \rightarrow+\infty} p\left(A_{i} x_{2 n}, y\right)=\lim _{n \rightarrow+\infty} p\left(T x_{2 n+1}, y\right)=0$

And $\lim _{n \rightarrow+\infty} p\left(A_{j} x_{2 n-1}, y\right)=\lim _{n \rightarrow+\infty} p\left(S x_{2 n}, y\right)=0$

Now we can suppose, without loss of generality, that $S X$ is a closed subset of the partial metric space $(X, p)$. From $(2.15)$, there exists $u \in X$ such that $y=S u$. We claim that $p\left(A_{i} u, y\right)=0$. Suppose, to the contrary, that $p\left(A_{i} u, y\right)>0$.

$$
\begin{aligned}
p\left(y, A_{i} u\right) & \leq p\left(y, A_{j} x_{2 n+1}\right)+p\left(A_{i} u, A_{j} x_{2 n+1}\right)-p\left(A_{j} x_{2 n+1}, A_{j} x_{2 n+1}\right) \text { for }(i \neq j) \\
& \leq p\left(y, A_{j} x_{2 n+1}\right)+p\left(A_{i} u, A_{j} x_{2 n+1}\right) \\
& \leq p\left(y, A_{j} x_{2 n+1}\right)+\phi\left(\max \left\{p\left(y, y_{2 n}\right), p\left(A_{i} u, y\right), p\left(y_{2 n+1}, y_{2 n}\right)\right\}\right)
\end{aligned}
$$

Since $\phi$ is continuous, from (2.12), and letting $n \rightarrow \infty$ we obtain

$$
\begin{aligned}
p\left(y, A_{i} u\right) & \leq \lim _{n \rightarrow+\infty}\left[p\left(y_{n}, y_{2 n+1}\right)+\phi\left(\max \left\{p\left(y, y_{2 n}\right), p\left(A_{i} u, y\right), p\left(y_{2 n+1}, y_{2 n}\right)\right\}\right)\right] \\
& =\lim _{n \rightarrow+\infty} p\left(y_{n}, y_{2 n+1}\right)+\phi\left(\lim _{n \rightarrow+\infty} \max \left\{p\left(y, y_{2 n}\right), p\left(A_{i} u, y\right), p\left(y_{2 n+1}, y_{2 n}\right)\right\}\right) \\
& =\phi\left(p\left(A_{i} u, y\right)\right)
\end{aligned}
$$

Hence, as we supposed that $p(A u, y)>0$ and as $\phi(t)<t$ for $t>0$,

We have $p\left(y, A_{i} u\right)<p\left(y, A_{i} u\right)$ which is a contraction.

Therefore,

$p\left(A_{i} u, y\right)=0 \Rightarrow y=A_{i} u$.

Since $y=S u$, then $A_{i} u=S u$, that is a coincidence point of $A_{i}$ and $S$. Hence the proof of (i). Since $A_{i} x \subseteq T X$ and (2.16), we have $y \in T X$. Therefore there exists $v \in X$ such that $y=T v$. We claim that $p\left(A_{j} v, y\right)=0$. Suppose, to the contrary, that $p\left(A_{j} v, y\right)>0$. From (2.1) and here $y=S u=A_{i} u=T v$

we have $p\left(y, A_{i} v\right)=p\left(A_{i} u, A_{i} v\right)$

$$
\leq \phi\left(\max \left\{p(S u, T v), p\left(A_{i} u, S u\right), p\left(A_{j} v, T v\right)\right\}\right)
$$




$$
\begin{aligned}
& \leq \phi\left(\max \left\{p(y, y), p(y, y), p\left(A_{j} v, y\right)\right\}\right) \\
& \leq \phi\left(p\left(A_{j} v, y\right)\right) \\
& <p\left(A_{j} v, y\right)
\end{aligned}
$$

This is contradiction. Then, we deduce that $p\left(A_{j} v, y\right)=0$ and $y=A_{j} v=T v$.

Therefore $v$ is a coincidence point of $A_{j}$ and $T$, then (ii) holds. Since the pair $\left\{A_{i}, S\right\}$ is weakly compatible, from (2.16), we have $A_{i} y=A_{i} S u=S A_{i} u=S y$. We claim that $p\left(A_{i} y, y\right)=0$. Suppose, to the contrary, that $p\left(A_{i} y, y\right)>0$. We have $p\left(A_{i} y, y\right) \leq p\left(A_{i} y, y_{2 n+1}\right)+p\left(y_{2 n+1}, y\right)$

$$
\begin{aligned}
& =p\left(A_{i} y, A_{j} x_{2 n+1}\right)+p\left(y_{2 n+1}, y\right) \\
& \leq \phi\left(\max \left\{p\left(S y, T x_{2 n+1}\right), p\left(A_{i} y, S y\right), p\left(A_{j} x_{2 n+1}, T x_{2 n+1}\right)\right\}\right)+p\left(y_{2 n+1}, y\right) \\
& \leq \phi\left(\max \left\{p\left(A_{i} y, y_{2 n}\right), p\left(A_{i} y, A_{i} y\right), p\left(y_{2 n+1}, y_{2 n}\right)\right\}\right)+p\left(y_{2 n+1}, y\right) \\
& \leq \phi\left(\max \left\{p\left(A_{i} y, y\right), p\left(A_{i} y, A_{i} y\right), 0\right\}\right) \\
& \leq \phi\left(p\left(A_{i} y, y\right)\right) \\
& \leq p\left(A_{i} y, y\right)
\end{aligned}
$$

Which is a contradiction. Then we deduce that

$p\left(A_{i} y, y\right)=0$ and $A_{i} y=S y=y$

Since the pair $\left\{A_{j}, T\right\}$ is weakly compatible, from (2.17), we have $A_{j} y=A_{j} T v=T A_{j} v=T y$. We claim that $p\left(A_{j} y, y\right)=0$.

Suppose, to the contrary, that $p\left(A_{j} y, y\right)>0$, then by (2.1) and (2.19), we have

$p\left(y, A_{j} y\right)=p\left(A_{i} y, A_{j} y\right)$

$$
\begin{aligned}
& \leq \phi\left(\max \left\{p(S y, T y), p\left(A_{i} y, S y\right), p\left(A_{j} y, T y\right)\right\}\right) \\
& \leq \phi\left(\max \left\{p\left(y, A_{j} y\right), p(y, y), p\left(A_{j} y, A_{j} y\right)\right\}\right) \\
& \leq p\left(A_{j} y, y\right)
\end{aligned}
$$

This is a contradiction. We deduce that

$p\left(A_{j} y, y\right)=0$ and $A_{j} y=T y=y$.

Now, combining (2.19) and (2.20), we obtain

$y=A_{i} y=A_{j} y=S y=T y, i \neq j$.

That is, $y$ is a common fixed point of $A_{i}, A_{j}, S$ and $T$.

\section{Uniqueness:}

Let us suppose that $z \in X$ is a common fixed point of $A_{i}, A_{j}, S$ and $T$ with $p(z, y)>0$.

Using(2.1), we get

$$
\begin{aligned}
p(y, z) & =p\left(A_{i} y, A_{j} z\right) \\
& \leq \phi\left(\max \left\{p\left(A_{i} y, A_{j} z\right), p\left(A_{i} y, A_{j} y\right), p\left(A_{j} z, A_{j} z\right)\right\}\right) \\
& =\phi(\max \{p(y, z), p(y, y), p(z, z)\}) \\
& =\phi(p(y, z))<p(y, z)
\end{aligned}
$$

Which is contradiction. Then we deduce that $z=y$. Therefore, the uniqueness of the common fixed point is proved.

Corollary 2.4: Suppose that $A, B, S$ and $T$ are self maps of a complete partial metric space $(X, p)$ such that $A X \subseteq T X, B X \subseteq S X$ and

$$
p(A x, B y) \leq \phi(\max \{p(S x, T y), p(A x, S x), p(B y, T y)\})
$$

For all $x, y \in X$ where $\phi \in \Phi$ if one of the ranges $A X, B X, T X$ and $S X$ is a closed subset of $(X, p)$, then (i) $A$ and $S$ have coincidence point. Moreover, if the pairs $\{A, S\}$ and $\{B, T\}$ are weakly compatible, then $A, B, S$ and $T$ have a unique common fixed point.

Corollary 2.5: Suppose that $S$ and $T$ are self maps of a complete partial metric space $(X, p)$ such that $T X \subseteq S X$ and for all $x, y \in X$ where $\quad \phi \in \Phi$

$$
p(T x, T y) \leq \phi\left(\max \left[p(S x, S y), \frac{(p(T x, S x)+p(T y, S y))}{2}+\frac{(p(T y, S x)+p(T x, S y))}{2}\right]\right)
$$

and

if one of the ranges $T X$ and $S X$ is a closed subset of $(X, p)$, then (i) $S$ and $T$ have coincidence point. (ii) Moreover, if the pairs $\{S, T\}$ is weakly compatible, then $S$ and $T$ have a unique common fixed point. 


\section{REFERENCES}

[1] M. Aamri and D.El Moutawakil, common fixed points under contractive conditions in symmetric spaces, Appl. Math. E-Notes 3(2003), 156 162.

[2] M. Aamri and D.El Moutawakil, some new common fixed point theorems under strict contractiveconditions, J. Math. Anal. Appl. 270 (2002), $181-188$.

[3] R. P. Pant, Common fixed points of sequences of mappings, Ganita, 47 (1996) $43-49$.

[4] Ljubomir Ciric, Bessem Samet, HassenAydi, Galogero Vetro, common fixed points of generalized contractions on partial metric spaces and an application, Applied Mathematics and Computation 218 (2011) 2398 - 2406.

[5] Duran Turkoglu and Ishak Altun A Common fixed point theorem for weakly compatible mappings insymmetric spaces satisfying an implicit realtion Bol. Soc. Mat. Mexicana (3) Vol.13. 2007.

[6] R. P. Pant, Common fixed points of contractive maps, J. Math. Anal. Appl., 226 (1998) 251 - 258.

[7] S. Sessa, On a weak commutatively condition of mappings in fixed point considerations, Publ. Int., Math.(Belgrad), 32 (1982), 149 - 153.

[8] G. Jungck, Compatible mappings and common fixed points, Intl. J. Math. Sci., 9(1986) 771 - 779.

[9] J. Jachymski, Common fixed point theorems for some families of maps, Ind.J. Pure Appl. Math., 25 (1994)925 - 937.

[10] G.Jungck, K. B. Moon, S. Park and B. E. Rhodes, on generalization of the meir -keeler type contraction maps coeerctions, J. Math. Anal. Appl., $180(1993) 221-222$.

[11] I. Altun, H. A. Hancer and D. Tuekoglu, A fixed point theorem for multi - maps satisfying an implicitrelation on metrically convex metric spaces, Math. Commun. 11 (2006), $17-23$.

[12] R. Krishnakumar, K. Dinesh, D. Dhamodharan, Some fixed point theorems $\varphi-\psi$ weak contraction on Fuzzy Metric spaces, International Journal of Scientific Research in Mathematical and Statistical Sciences, Volume-5, Issue-3, pp.146- 152, June (2018)

[13] T. L. Hicks and B. E. Rhoades, Fixed point theory in symmetric spaces with applications to probabilistic spaces, Nonlinear Anal., 36 (1999) $331-344$.

[14] R. Krishnakumar and T. Mani, Common fixed point of contractive modulus on complete metric space,International Journal of Mathematics And its Applications, 5(4 - D) (2017), 513 - 520.

[15] G. Jungck, Common fixed points for non continuous non self maps on non metric spaces, for East J. Math.Sci. (4) (2), (1996), 199 - 215.

[16] S. G. Matthews, Partial metric topology, in: Proceedings Eighth Summer Conference on General Topology and Application, in: Ann. New York Acad. Sci. 728 (1994) $184-197$.

\section{AUTHORS PROFILE}

Dr. R. Krishnakumar is the Associate Professor and Head of the PG \& Research Department of Mathematics, Urumu Dhanalakshmi College. He has above 22 years experience in teaching. His field of research is Fixed point theory.

R. Livingston is pursuing his Ph.D in PG \& Research Department of Mathematics, Urumu Dhanalakshmi College, Trichy. His field of research is Fixed point theory. 